\title{
Aspir üretiminde enerji bilançosunun belirlenmesi (Sivas ili Gürün ilçesi örneği)*
}

\author{
Ebubekir ALTUNTAȘ ${ }^{\circledR 1}$, Mustafa GÜZEL ${ }^{(1)}{ }^{1}$, Engin öZGöZ ${ }^{\circledR}{ }_{1}$
}

1Tokat Gaziosmanpaşa Üniversitesi, Ziraat Fakültesi, Biyosistem Mühendisliği Bölümü, Tokat

*Bu çalışma, Mustafa Güzel tarafindan hazırlanan 'Sivas-Gürün şartlarında aspir üretiminde farklı toprak işleme sistemlerinin enerji kullanım etkinliği açısından karşılaştırılması' konulu yüksek lisans tezinin bir bölümüdür.

Alınış tarihi: 11 Mart 2019, Kabul tarihi: 25 Eylül 2019

Sorumlu yazar: Ebubekir ALTUNTAȘ, e-posta: ebubekir.altuntas@gop.edu.tr

$\ddot{0} \mathbf{z}$

Bu çalıșmada, Türkiye'nin Sivas ilinin Gürün ilçesinde, aspir üretimindeki enerji bilançosu, 4 farklı (0-10 da, 10.01-20 da, 20.01-40 da ve $>40 \mathrm{da})$ işletme büyüklüklerine göre gayeli örnekleme yöntemiyle belirlenmiștir. Çalışmada, 2017 üretim sezonunda, 82 işletme ile yüz yüze anket yapılarak enerji çıktı/girdi oranı belirlenmiştir. Aspir üretiminde, işletme büyüklüklerine göre en büyük enerji girdisi ve çıktısı $>40$ da işletme büyüklüğünde sirasıyla $113858 \mathrm{MJ} \mathrm{ha}^{-1}$ ve $314300 \mathrm{MJ} \mathrm{ha}^{-1}$ olarak hesaplanmıştır. Ayrıca, en yüksek enerji çıktı / girdi oranı da $>40$ da işletme için 2.78 olarak belirlenmiștir. Enerji girdilerinin işletme büyüklüklerine göre dağılımında; en yüksek enerji girdisinin kimyasal gübre enerjisi olduğu ve toplam girdi içerisindeki payının da 0-10 da, 10.01-20 da, 20.01-40 da ve $>40$ da için sırasılyla \%50.76, \%56.54, $\% 61.52$ ve $\% 72.78$ olduğu bulunmuștur. Aspir üretiminde en yüksek enerji kullanım etkinliği, özgül enerji ve net enerji $>40$ da işletme büyüklüğü için sirasiyla 2.78; $14.75 \mathrm{MJ} \mathrm{kg}^{-1}$ ve $200442.09 \mathrm{MJ} \mathrm{ha}^{-1}$ olarak hesaplanmıştır.

Anahtar kelimeler: İşletme büyüklüğü, aspir, enerji çıktı/girdi oranı, özgül enerji

Determination of energy balance in safflower production (a case study for Gürün-Sivas province)

\footnotetext{
Abstract

In this study, the energy balance of safflower production has been identified in Gürün district of
}

Sivas-Turkey. In order to determine the energy balance, 4 different safflower agricultural enterprise sizes (0-10 da, 10.01-20 da, 20.01-40 da and $>40 \mathrm{da}$ ) were determined with the purposeful sampling method. In this study, the faceto-face surveys and observations were made with 82 agricultural enterprises, and the energy output/input ratio was determined during the 2017 production season. According to the agricultural enterprise sizes, the largest energy input in the production of safflower is $113858 \mathrm{MJ} \mathrm{ha}^{-1}$ and the energy output was calculated as $314300 \mathrm{MJ} \mathrm{ha}^{-1}$ for $>40$ da agricultural enterprise, respectively. The energy output/input ratio is highest in $>40$ da agricultural enterprises has been determined. The distribution of energy inputs according to their agricultural enterprise sizes (0-10 da, 10.01-20 da, 20.01-40 da and $>40 \mathrm{da}$ ) were found as highest with $50.76 \%, 56.54 \%, 61.52 \%$ and $72.78 \%$ for the chemical fertilizer energy, respectively. The highest energy use efficiency, specific energy and net energy for safflower production was found to be $2.78 ; 14.75$ $\mathrm{MJ} \mathrm{kg}^{-1}$ and $200442.09 \mathrm{MJ} \mathrm{ha}^{-1}$, respectively.

Key words: Enterprise size, safflower, energy output/input ratio, specific energy

\section{Giriş}

Günümüzde yapılan tarımsal üretimin yalnız kârlılığı düşünülmemeli, aynı zamanda çevresel, sosyal ve tarımsal boyutları da dikkate alınmal, yenilenemeyen veya yenilenmesi uzun zaman alan doğal kaynakların korunması ve çevre kirliliğinin azaltılması, tarımsal sürdürülebilirlik açısından göz önünde tutulmalıdır (Berkman, 1996). Tarımsal 
üretimde girdi ve çıtı değerlerinin, güncel ve bilimsel rakamlarla ölçülebilmesi, bu değerlerin ortak bir ifade ile anlamlandırılması, üzerinde durulması gereken önemli bir konudur (Işıklı ve Işın, 1991). Tarımsal üretim içerisinde, verimliliğin ve ekonomik programların zamanında gerçekleşmesinde dikkate alınacak önemli üretim unsurlarından birisi de tarımsal mekanizasyon uygulamalarıdır.

Gelişmekte olan ülkelerde tarımsal mekanizasyona ayrılan pay, üretim giderlerinde gübreden sonra ikinci sırayı alırken, gelişmiş ülkelerde ise en yüksek orana sahiptir (Gifford, 1986). Bu pay işletmeler için tüm üretim giderleri ve sermayenin \%50'si kadardır (Cross, 1998). Bitkisel üretimde en büyük enerji ihtiyacı toprak işleme uygulamalarında görülmektedir. Günümüzde uygulanmakta olan geleneksel toprak işleme sistemlerinin yüksek enerji kullanımı, bitkisel üretim zincirinde alternatif toprak işleme sistemlerinin uygulanması gerektiğini göstermektedir.

Aspir (Carthamus tinctorius L) bitkisi, \%30-50 yağ oranına sahip olup, çoğunlukla yağ üretiminde kullanılmakla beraber boya, vernik, margarin, yem sanayinde, ilaç sanayinde, bitkisel çay olarak ve daha önemlisi biyodizel üretimi için kullanılmaktadır. Ayrıca; kuru çiçek ve yeşil çit olarak süs bitkileri içerisinde de yer almaktadır (Rahamatalla ve ark., 1998; Wang ve ark., 1999 Weiss, 2000; Öğüt ve Oğuz (2006).

Ülkemizin iklim ve toprak koşulları, yağlı tohumlu bitkilerin üretimi için elverişli olmasına rağmen, üretim miktarları ihtiyacı henüz karşılayamamaktadır. Ülkemizde bitkisel yağ ve yağlı tohum ihtiyacının karşılanabilmesi için potansiyel ekim alanlarının genişletilmesi ve verimin artırılması gerekir. Agronomik tedbirlerin tam ve zamanında uygulanması ile kuraklığa, tuzluluğa ve soğuğa olan yüksek toleransı, erozyonu önlemesi ve önemli hastalık ve zararlılarının olmaması, ikinci ürün ve münavebe sistemi içerisinde yer alması nedenleriyle aspir bitkisinin üretimine mutlak yer verilmesi, bitkisel yağ ve yağlı tohum ihtiyacının karşılanması açısından önemlidir. Aspir bitkisi, Türkiye coğrafyasında İç Anadolu, Doğu ve Güneydoğu Anadolu Bölgelerinde ekim nöbetinde değerlendirilerek nadas alanlarında yetiștirilebilecek öneme sahiptir (Kurt ve ark., 2011). Ayrıca, aspir üretimi için en önemli avantaj, özellikle İç Anadolu bölgesinde yoğun şekilde yer alan tahıl (buğday, arpa vb.) üretiminde, toprak hazırlığından ürün depolamaya kadar geçen sürede kullanılan tarımsal alet-ekipmanların aspir bitkisinin tarımında da kullanılabilmesinin mümkün olmasıdır (Babaoğlu, 2007).

İç Anadolu Bölgesinde yer alan Sivas ili 27202 km²'lik alanı ile Türkiye'nin en büyük yüzölçümüne sahip ikinci ilidir. Sivas ili bitkisel üretiminde, hububat ağırlıklı bir üretim söz konusu olsa da, yağlı tohumlu bitkilerin ekimi son yıllarda önemli oranda artış göstermiştir. Bu kapsamda, Sivas ilinde yağlı tohumlu bitkilerin ekim alanı 2016 yılında toplamda 19110 dekar seviyesine yükselmiştir. Sivas ili genelinde en fazla aspir üretimi 10000 dekar alan ve 750 ton üretimle Gürün ilçesinde gerçekleşmiştir (Anonim, 2016). Sivas ili tarım alanlarının 2519043 hektarı rüzgâr ve su erozyonu etkisinde olup, sürdürülebilir bir tarımsal üretim sistemine geçilmeli, toprak ve su kaynaklarını koruyan ve erozyon tehdidini azaltan toprak işleme sistemleri uygulanmalıdır (Anonim, 2014).

Tarımsal üretimle ilgili olarak yapılacak enerji analizleri, tarımsal sistemlerin enerji tüketimi açısından tanımlanıp gruplandırılmasında önemli bir yaklaşımdır. Son yıllarda sürdürülebilir tarım ilkeleri doğrultusunda tarımsal üretimin değerlendirilmesinde ekonomi, enerji ve emisyon (çevre) birlikte incelenmektedir. Her geçen yıl enerji ihtiyacının giderek arttığı tarım sektöründe, toprak işleme sistemlerindeki enerji etkinliğinin artırılması, enerjiye olan ihtiyacı azaltarak, üretimde elde edilen verimliliği artıracaktır.

Son yıllarda, Türkiye'de farklı bölgelerde, tarımsal üretimde farklı ürünlerde enerji kullanım etkinliğinin incelendiği birçok çalışma mevcuttur (Gözübüyük ve ark., 2012; Karaağaç ve ark., 2014; Baran ve Karağaç, 2014; Baran ve Gökdoğan., 2016; Özgöz ve ark., 2017; Altuntaş ve ark., 2018; Altuntaş ve ark., 2019). Farklı bölgelerde, işletme büyüklükleri açısından tarımsal üretimde farklı ürünlerde enerji kullanım etkinliğinin araştırıldığı birçok araştırmalar yapılmıştır. Örneğin; Unakıtan ve ark. (2010), kolza üretim enerji etkinliğinin işletme büyüklükleri ( $<5$ ha, 5-9.9 ha ve $>10$ ha) için araştırdığı çalışmasında, enerji verimliliğini sırasıyla, $4.43,4.68$ ve 5.23 , net enerji üretimini ise, $62584 \mathrm{MJ}$ ha-1, $69836 \mathrm{MJ} \mathrm{ha}^{-1}$ ve $74405 \mathrm{MJ}^{-1}$ olarak hesaplamışlardır.

Singh ve ark. (2000), Hindistan Punjap yöresinde pamuk üretiminin farklı işletme büyüklükleri $(<1$ ha, 1-2 ha arası, $2-4$ ha arası ve $>4$ ha) için toplam enerji tüketim değerlerini sırasıyla; 8 894, 10 393, 9985 ve 
$11342 \mathrm{MJ} \mathrm{ha}^{-1}$ olarak hesaplamışlardır. İşletme büyüklüklerine göre enerji girdilerinin arttığını, üretim girdilerindeki \%1-3 oranındaki artışın pamuk verimini \%6-8 arttırdığını açıklamıșlardır. Șehri (2012), Çukurova bölgesinde pamuk bitkisi yetiştiriciliğinin enerji etkinliğini incelediği bir anket çalışmasında, yetiştirme alanı büyüklüklerine göre, işletmeleri 0.1-5 ha, 5.1-10 ha ve >10 ha olarak üç gruba ayırarak incelemiştir. Çalışmada, pamuk üretiminde toplam enerji girdisini işletme grupları için sırasıyla $35882.22 \mathrm{MJ} \mathrm{ha}^{-1}, 33950.25 \mathrm{MJ} \mathrm{ha}^{-1}$ ve $34889.13 \mathrm{MJ} \mathrm{ha}^{-1}$ olarak hesaplamış ve işletme büyüklüğü arttıkça enerji tüketimlerinin azaldığını, ayrıca, toplam enerji girdisi içerisinde gübre enerjisi girdisinin payının işletme grupları için sırasıyla \%40.3, \%37.71 ve \%39.85 olduğunu belirlemiştir.

Her türlü girdinin etkin kullanılması, işletmelerin ekonomik kazancı ve çevreye olan etkisini eniyilemesi açısından tarımsal üretimde etkin enerji kullanımı gereklidir. Enerji analizleri yardımıyla elde edilen sonuçlar, ișletmelerde enerjinin ne derece etkin kullanıldı̆̆ dolayısıyla kaynakların verimli yönetimi açısından oldukça önemlidir. Türkiye'de ve dolayısıyla İç Anadolu Bölgesinde aspir bitkisi tarımında farklı işletme büyüklükleri için enerji kullanım etkinliklerinin belirlenmesine yönelik yapılmış bir çalışma bulunmamaktadır. Bu nedenle, bu çalışmada, İç Anadolu bölgesi, Sivas ili Gürün ilçesinde, kuru tarım alanlarında aspir tarımı için enerji etkinliğinin işletme büyüklükleri bazında belirlenmesiyle, üretim planlamasına yönelik temel veriler oluşturulması amaçlanmıştır.

\section{Materyal ve Metot}

Sivas Gıda, Tarım ve Hayvancılık İl Müdürlügü̈'nden alınan bilgiler doğrultusunda, Sivas ilinde aspir üretimini temsil edecek sayı ve yoğunluğa sahip olan ilçeler belirlenmiş, bu ilçeler içerisinde Gürün ilçesi gayeli örnekleme metoduna göre en fazla üretim alanına sahip ilçe olarak belirlenmiştir. Sivas ilinin en yoğun aspir üretimini gerçekleştiren Gürün ilçesinde, üretim yapmakta olan 82 işletmeci ile tam sayım yöntemiyle yüz yüze anket çalışması yapılmıştır (Arıkan, 2011). Aspir üreticileri işletme büyüklüklerine göre dört farklı gruba ayrılmıștır. Anket soruları içerisinde, çiftçilerin aspir tarımında kullandıkları alet ve makinaların (toprak ișleme, ekim, gübreleme, sulama, ilaçlama ve hasat) özellikleri, sarf malzeme miktarı ve ürün verimine ait bilgiler yanında tarımsal uygulamadaki işlem süreleri ve yakıt tüketimi bilgileri yer almaktadır. Bu anlamda, toplanan veriler bilgisayar ortamına aktarıldıktan sonra, Excel programı yardımıyla hesaplamalar yapılmış, tablolar oluşturulmuş ve analiz işlemleri gerçekleştirilmiştir.

Tarımda enerji kullanımı iki grupta (doğrudan enerji ve dolaylı enerji) incelenmektedir (Öztürk ve Barut, 2005). Aspir üretiminde doğrudan enerji girdileri yalnızca yakıt ve yağ sarfiyatından olmuştur. Yakıt tüketimi değerleri, anket verilerine bağlı olarak işletme büyüklüğü bazında elde edilmiştir. Yağ tüketimi değerleri ise, yakıt tüketiminin \%4.5'i olacak şekilde hesap edilmiștir (Özcan, 1985; Alpkent, 1984). Dolaylı enerji girdileri olarak; insan iş gücü enerjisi, alet-makina ve traktör imalat enerjisi, kimyasal gübre enerjisi, kimyasal ilaç enerjisi ve tohum enerjisi dikkate alınmıştır. Dolaylı enerji girdisi, Çizelge 1'de verilen enerji eş değerleri tablosundaki verilerin, kullanım miktarları ile çarpılması sonucu elde edilen enerji miktarlarının toplanmasıyla bulunmuştur. Alet ve makine imalat enerjisi eşitlik (1) kullanılarak hesaplanmıştır.

$$
M E=\frac{G \cdot E}{T \cdot C_{a}}
$$

Burada; $M E$ : Makina imalat enerjisi (MJ ha-1), G: Alet ve makina ağırlığı (kg), E: Enerji eşdeğeri (Çizelge 1), T: Makinanın ekonomik ömrü (h) ve $C_{a}$ : Tarla kapasitesi (ha h $\left.{ }^{-1}\right)^{\prime}$ dir.

Çalışmada elde edilen ürün (çıktı) aspir bitkisinin tohumlarıdır. Toplam enerji çıktısı, ürün verimi ve ürünün enerji eşdeğeri (Çizelge 1) çarpılarak hesaplanmıştır. Çalışmadaki aspir tohum verimi, anket verilerinden elde edilmiştir. Farklı işletme büyüklüklerine göre aspir tarımının enerji etkinliklerini karşılaştırmak için, öncelikle her bir işletme büyüklüğündeki toplam girdi ve toplam çıktı enerjileri ayrı ayrı hesaplanmıștır. Daha sonra, elde edilen değerler Çizelge 2'de verilen enerji etkinlik parametrelerinde kullanılmıştır.

Farklı işletme büyüklüklerine göre aspir tarımındaki enerji kullanım etkinliğinin karşılaştırılması için, SPSS 13 istatistik paket programı kullanılarak varyans analizi ve çoklu karşılaştırma testi (LSD) yapılmıştır.

\section{Bulgular ve Tartışma}

\section{Anket Verilerinin Değerlendirilmesi}

Sivas ili, Gürün İlçesinde, aspir üretimi yapan 82 işletmeci ile tam sayım yöntemiyle yapılan anket çalışması sonucu, aspir üreticileri işletme büyüklüklerine göre dört farklı gruba ayrılmıştır. 
Çizelge 1. Aspir üretiminde kullanılan girdi ve çıktı enerji eşdeğerleri

\begin{tabular}{cccc}
\hline Girdi & Birim & Enerji Eşdeğeri (MJ birim ${ }^{-1}$ ) & Kaynaklar \\
\hline İnsan İşücü & saat & 2.3 & Kizılaslan (2009) \\
Alet ve Makina & - & 121.3 & 158.3 \\
Traktör & - & 60.6 & Doering (1980) \\
Gübreler & & $1980)$ & \\
1) Azot, N & kilogram & 11.15 & Bojaca and Schrevens, (2010) \\
2) Fosfor, P & kilogram & 47.8 & Hetz, (1992) \\
3) Potasyum, K & kilogram & 42.5 & Hetz, (1992) \\
Yakıt (dizel) & litre & 238 & Zangeneh ve ark. (2010) \\
Yağ & litre & 14 & Acaroğlu (2006) \\
İlaç (herbisit) & kilogram & & Acaroğlu (2006) \\
Tohumluk & kilogram & 39.5 &
\end{tabular}

Çizelge 2. Enerji etkinlik parametreleri

\begin{tabular}{|c|c|c|}
\hline Gösterge & Tanım & Birim \\
\hline Enerji oranı & Toplam enerji çıktısı (MJ ha-1) / Toplam enerji girdisi (MJ ha-1) & - \\
\hline Özgül enerji & Toplam enerji girdisi $\left(\mathrm{MJ} \mathrm{ha}^{-1}\right) /$ Hasat edilen toplam ürün $\left(\mathrm{kg} \mathrm{ha}^{-1}\right)$ & MJ kg-1 \\
\hline Enerji üretkenliği & Hasat edilen toplam ürün $\left(\mathrm{kg} \mathrm{ha}^{-1}\right) /$ Toplam enerji girdisi $\left(\mathrm{MJ} \mathrm{ha}^{-1}\right)$ & $\mathrm{kg} \mathrm{MJ}^{-1}$ \\
\hline Net enerji verimi & Toplam enerji çıktısı (MJ ha-1) - Toplam enerji girdisi (MJ ha-1) & MJ ha-1 \\
\hline Enerji kârlılı̆̆ı & Net enerji (MJ kg-1) / Enerji girdisi $\left(\mathrm{MJ} \mathrm{kg}^{-1}\right)$ & - \\
\hline
\end{tabular}

Çizelge 3. Üretim alanlarına göre işletme grupları

\begin{tabular}{|c|c|c|c|c|}
\hline Üretim alanına göre gruplar & İşletme sayıları & $\%$ & $\begin{array}{l}\text { Toplam işletme alanı } \\
\text { (da) }\end{array}$ & $\%$ \\
\hline $0-10 \mathrm{da}$ & 32 & 39.02 & 168.02 & 9.51 \\
\hline $10.01-20 \mathrm{da}$ & 20 & 24.39 & 283.16 & 16.03 \\
\hline $20.01-40 \mathrm{da}$ & 16 & 19.51 & 423.76 & 24.00 \\
\hline$>40 \mathrm{da}$ & 14 & 17.07 & 891.25 & 50.46 \\
\hline Toplam & 82 & 100 & 1766.19 & 100 \\
\hline
\end{tabular}

Çizelge 4. Üretim alanlarına göre işletme gruplarındaki toprak işleme sistemlerinin dağılımı

\begin{tabular}{|c|c|c|c|c|}
\hline \multirow[b]{2}{*}{ Toprak işleme sistemi } & \multicolumn{4}{|c|}{ İşletme büyüklükleri } \\
\hline & $0-10 \mathrm{da}$ & $10.01-20.0 \mathrm{da}$ & $20.01-40.0 \mathrm{da}$ & $>40 \mathrm{da}$ \\
\hline Geleneksel (Kulaklı pulluk) & $\begin{array}{c}8 \text { işletme } \\
45.068 \mathrm{da} \\
\% 2.55\end{array}$ & $\begin{array}{c}3 \text { işletme } \\
46.962 \mathrm{da} \\
\% 2.66 \\
\end{array}$ & $\begin{array}{c}2 \text { işletme } \\
40.86 \mathrm{da} \\
\% 2.31 \\
\end{array}$ & $\begin{array}{c}1 \text { işletme } \\
49.99 \mathrm{da} \\
\% 2.83 \\
\end{array}$ \\
\hline Azaltılmış (goble disk) & $\begin{array}{c}24 \text { işletme } \\
122.95 \mathrm{da} \\
\% 6.96\end{array}$ & $\begin{array}{c}17 \text { işletme } \\
236.20 \mathrm{da} \\
\% 13.37\end{array}$ & $\begin{array}{c}14 \text { ișletme } \\
382.9 \mathrm{da} \\
\% 21.68\end{array}$ & $\begin{array}{c}13 \text { işletme } \\
841.26 \mathrm{da} \\
\% 47.63\end{array}$ \\
\hline Toplam & $\begin{array}{c}32 \text { işletme } \\
168.02 \mathrm{da} \\
\% 9.51\end{array}$ & $\begin{array}{c}20 \text { işletme } \\
283.162 \text { da } \\
\% 16.03 \\
\end{array}$ & $\begin{array}{c}16 \text { işletme } \\
423.76 \mathrm{da} \\
\% 24.00 \\
\end{array}$ & $\begin{array}{c}14 \text { işletme } \\
891.25 \mathrm{da} \\
\% 50.46 \\
\end{array}$ \\
\hline
\end{tabular}

İşletme büyüklüklerine göre ayrılan gruplar içerisindeki işletme sayıları ve toplam alanları Çizelge 3'te verilmiştir. Anket kapsamında işletmelerin geleneksel toprak işleme ve korumalı toprak işleme sistemi uyguladıkları belirlemiş ve toprak işleme sistemlerinin işletme büyüklüklerine göre dağılımları Çizelge 4'te verilmiştir. Çizelge 4'e göre, işletme büyüklüğü arttıkça goble diskin kullanıldığı azaltılmış toprak işleme sisteminin kullanımı da artmaktadır. İşletme büyüklüğü >40 da olan işletmelerin \%47.63'ünde, $0-10$ da büyüklüğündeki işletmelerin ise \%6.96'sında azaltılmış toprak işleme uygulanmaktadır. Toplam işletme sayısının yaklaşık \%90'lık bölümünde, geleneksel toprak işleme sistemleri yerine alternatif korumalı toprak işleme sistemleri kullanılmaktadır. Bu sonuçlar, Sivas ili Gürün ilçesinde aspir üretimi yapan işletmelerinin korumalı toprak işleme sistemlerine olan talebinin ve bu sistemleri kullanımlarının büyük ölçüde olumlu olduğunu göstermektedir. Aspir üretiminde işletmeler genel olarak, ekim işleminde hububat ekim makinası, gübreleme de santrifüj gübre dağıtma makinası ve 
ilaçlama için tarla pülverizatörü ve hasat işleminde ise biçerdöver kullanmaktadırlar.

Gürün ilçesinde aspir üreten işletmelerin, işletme sayısı olarak en yoğun olduğu grup 0-10 da büyüklüğündeki işletmeler olduğu görülmektedir. İşletme sayılarının \%39'unu oluşturan bu grubun toplam işletme alanı 168.02 da'dır. Bu değer, Gürün ilçesinde aspir üretimi yapılan toplam alanın ise \%10'unu oluşturmaktadır. İlçede üretim yapılan alanların yaklaşı \%51'ini ise $>40$ da olan işletmeler oluşturmaktadır.

\section{Aspir üretiminde enerji etkinliklerinin belirlenmesi}

Gürün ilçesinde, üretim alanı büyüklüklerine göre gruplara ayrılan işletmelerin, üretim için kullandıkları enerji girdi değerleri Çizelge 5'te gösterilmiştir. Çizelge 5 incelendiğinde, Sivas ili Gürün ilçesinde aspir üretimi yapan tüm işletmelerin toplam enerji girdi ve enerji çıtılarının, işletme büyüklüklerine göre artış gösterdiği görülmektedir.

Çizelge 5. İşletme büyüklüklerine göre aspir üretiminde enerji girdisi değerleri (MJ ha-1)

\begin{tabular}{|c|c|c|c|c|c|c|c|c|}
\hline \multirow{2}{*}{ Girdi türleri } & \multicolumn{8}{|c|}{ İșletme büyüklükleri } \\
\hline & $0-10 \mathrm{da}$ & $\%$ & $10.01-20 \mathrm{da}$ & $\%$ & $20.01-40 \mathrm{da}$ & $\%$ & $>40 \mathrm{da}$ & $\%$ \\
\hline \multicolumn{9}{|l|}{ Doğrudan enerji } \\
\hline Yakıt & 686.26 & 5.05 & 1840 & 5.65 & 3453 & 6.16 & 8316 & 7.30 \\
\hline Yağ & 25.60 & 0.19 & 25.14 & 0.08 & 24.99 & 0.04 & 24.66 & 0.02 \\
\hline \multicolumn{9}{|l|}{ Dolaylı enerji } \\
\hline İnsan iș gücü & 4.09 & 0.03 & 10.42 & 0.03 & 18.71 & 0.03 & 43.88 & 0.04 \\
\hline Makina imalat & 374.87 & 2.76 & 377.65 & 1.16 & 378.58 & 0.68 & 380.55 & 0.33 \\
\hline Kimyasal gübre & 6903 & 50.76 & 18429 & 56.54 & 34473 & 61.52 & 82861 & 72.78 \\
\hline Pestisit & 5235 & 38.50 & 10922 & 33.51 & 15837 & 28.26 & 17776 & 15.61 \\
\hline Tohum & 371.2 & 2.73 & 991.1 & 3.04 & 1854 & 3.31 & 4456 & 3.91 \\
\hline Toplam & 13599 & 100 & 32595 & 100 & 56039 & 100 & 113858 & 100 \\
\hline Çıktı Enerjisi & 12406 & & 39874 & & 97113 & & 314300 & \\
\hline
\end{tabular}

Tüm işletme gruplarında, enerji girdi değerleri içerisinde en yüksek paya kimyasal gübre girdisi sahiptir. 0-10 da, 10.01-20 da, 20.01-40 da ve $>40$ da işletme büyüklük grupları için toplam enerji girdisi içerisinde kimyasal gübre enerjisi girdisinin payı sirasiyla; \%50.76, \%56.54, \%61.52 ve \%72.78 olmaktadır. Kimyasal gübre enerjisinden sonra en yüksek enerji girdisinin kimyasal ilaç enerjisi olduğu ve kimyasal ilaç enerji girdisinin toplam girdi içerisindeki payının işletme büyüklük grupları için sirasiyla; \%38.50, \%33.51, \%28.26 ve \%15.61 olduğu belirlenmiștir. Önemli üretim girdilerinden biri olan yakıt girdisi enerjisi ise işletme büyüklük gruplarına göre, sirasılyla; \%5.05, \%5.65, \%6.16, $\% 7.30$ değerlerindedir. Aspir üretiminde işletme alanı büyüdükçe kimyasal gübre kullanımı da enerji ihtiyacı içerisinde yüksek oranlara ulaşmıştır.

Farklı bölgelerde ve farklı ürünlerle yapılan birçok çalışmada da toplam enerji girdisi içerisindeki en büyük payın kimyasal gübre enerji girdisinin olduğu, bunu genellikle yakıt enerji girdisinin takip ettiği belirtilmiştir (Shahin ve ark., 2008; Golaszewski ve ark., 2014; Özgöz ve ark., 2017). Kardoni ve ark. (2015) buğday tarımında ve Allali ve ark. (2017) da patates tarımında en yüksek enerji girdisinin gübre enerji girdisi olduğunu ve bunu sulama suyu enerji girdisinin takip ettiğini, Pishgar-Komleh ve ark.
(2011) silaj mısır tarımında en yüksek enerji girdilerinin sırasıyla yakıt ve gübre enerji girdisi olduğunu, Altuntaș ve ark. (2019) ise buğday tarımında en yüksek enerji girdilerinin gübre ve tohum enerji girdisi olduğunu belirtmişlerdir. Sahahin ve ark. (2008) buğday tarımında hektar başına enerji kullanımının küçük arazilerde \%5.8 daha yüksek olduğunu ve arazi büyüklüğü arttıkça azaldığını, toplam enerji girdisinin çiftlik alanı büyüdükçe azaldığını toplam enerji çıktısının ise arttığını ifade etmişlerdir. Benzer şekilde Sefeedpari ve ark. (2012)'nın yaptığı çalışmada ise silaj mısır tarımında arazi büyüklüğü arttıkça toplam enerji girdisi azalmakta, toplam enerji çıktısı ise artmaktadır. Allali ve ark. (2017) soğan ve patates tarımında parsel boyutunu artırmanın her zaman enerji kullanım etkinliğini artırmadığını, toplam enerji girdisi ve enerji çıktısının alan büyüdükçe arttığını ve alandaki artışla enerji korumada çok az tasarruf olabileceğini belirtmişlerdir. Sonuçlardaki farklılığının, yetiștirilen ürün, üretim deseni, iklim, yetiştirme yöntemi ve üretim girdileri ve üretimdeki kullanılan alet ve makina farklıklarından kaynaklandığı düşünülmektedir. Golaszewski ve ark. (2014) buğday üretiminde enerji girdisinin Avrupa'nın iklim bölgeleri arasında oldukça farklı olduğunu, doğrudan enerji girdilerinin azaltılmasını 
anıza ekim veya azaltılmış toprak işleme sistemlerinin uygulanması ve dolaylı enerji girdilerinin azaltılmasını ise hassas tarım ve fosfor kullanımının kısıtlanması ile ilişkilendirmişlerdir. Kardoni ve ark. (2015) toprak işleme, hasat ve diğer tarımsal işlemleri modifiye ederek gübre etkinliğinin iyileştirilmesi ve yakıt tüketiminin azaltılmasının İran'daki buğday üretiminin enerji etkinliğini önemli ölçüde etkileyebileceğini ifade etmişlerdir. Bu değerlendirmelere göre; aspir üretimi için kimyasal gübrenin efektif uygulanması, gübre kullanımını azaltacak tedbirlerin alınması ve yeni münavebe sistemlerinin kullanılarak enerji girdisi miktarlarının düşürülmesi gerekmektedir. Anketlerden elde edilen veriler ile 4 farklı işletme grubundaki (0-10 da, 10.01-20 da, 20.01-40 da ve $>40$ da) enerji etkinlikleri hesaplanarak, Çizelge 6'da verilmiştir.

Çizelge 6. İşletme büyüklüklerine göre aspir üretiminde ortalama enerji etkinlik parametreleri

\begin{tabular}{ccccc}
\hline \multirow{2}{*}{$\begin{array}{c}\text { İşletme } \\
\text { büyüklükleri }\end{array}$} & Enerji oranı & $\begin{array}{c}\text { Özgül enerji } \\
\left(\mathrm{MJ} \mathrm{kg}^{-1}\right)\end{array}$ & $\begin{array}{c}\text { Enerji üretkenliği } \\
\left(\mathrm{kg} \mathrm{MJ}^{-1}\right)\end{array}$ & $\begin{array}{c}\text { Net enerji } \\
\left.(\mathrm{M}) \mathrm{ha}^{-1}\right)\end{array}$ \\
\cline { 2 - 5 } & $1.17 \mathrm{a}^{*}$ & $34.52 \mathrm{a}^{*}$ & $0.0296 \mathrm{a}^{*}$ & $2233.10 \mathrm{a}^{*}$ \\
$10-10 \mathrm{da}$ & $1.48 \mathrm{~b}$ & $27.51 \mathrm{~b}$ & $0.0375 \mathrm{~b}$ & $0.1689 \mathrm{a}^{*}$ \\
$20.01-40 \mathrm{da}$ & $1.93 \mathrm{c}$ & $21.30 \mathrm{c}$ & $0.0489 \mathrm{c}$ & $0.4813 \mathrm{~b}$ \\
$>40 \mathrm{da}$ & $2.78 \mathrm{~d}$ & $14.75 \mathrm{~d}$ & $0.0705 \mathrm{~d}$ & $0.9299 \mathrm{c}$ \\
\hline
\end{tabular}

*Aynı sütundaki aynı harfler arası farklar önemsizdir $(\mathrm{P}<0.01)$.

Çizelge 6'da görüldüğü gibi, işletme alanı büyüklüğü arttıkça kârlılık ve enerji üretkenliği artmaktadır. İşletme büyüklüklerinin enerji parametreleri üzerine etkisi $\mathrm{P}<0.01$ düzeyinde istatiksel olarak önemli bulunmuştur. Net enerji veriminde 0-10 da ve 10.0120 da işletme büyüklükleri istatiksel olarak aynı grupta yer almıștır. En önemli enerji etkinlik parametrelerinden birisi olan enerji kârlılığına bakıldığında, $>40$ da alanlarda yapılan aspir üretiminin enerji kârlılığının 0-10 da büyüklüğündeki üretim alanındaki enerji kârlılığının 6.84 katı olduğu görülmektedir. Bu durum alet ve makinaların daha efektif kullanımı, tarla kapasitelerinin yükselmesi ile birlikte yakıt tüketiminin azalması ve üretim sistemlerinin daha verimli kullanılması anlamına da gelmektedir.

Şehri (2012), pamuk tarımında 0.1-5 ha, 5.1-10 ha ve $>10$ ha olarak işletme grupları için enerji oranlarını sırasıyla; 1.56, 1.49 ve 1.63 olarak bulmuştur. Unakitan ve ark. (2010), Trakya bölgesinde kanola üretiminin enerji etkinliğini incelediği çalışmada $<5$ ha, 5-9.9 ha ve >10 ha işletme gruplarına göre; enerji çıktı/girdi oranlarını sırasıyla $4.43,4.68$ ve 5.23; özgül enerji değerlerini sırasıyla $6.23 \mathrm{MJ} \mathrm{kg}^{-1}, 5.89 \mathrm{MJ}$ $\mathrm{kg}^{-1}$ ve $5.28 \mathrm{MJ} \mathrm{kg}^{-1}$; enerji üretkenliğini sırasıyla 0.16 $\mathrm{kg} \mathrm{MJ}-1,0.17 \mathrm{~kg} \mathrm{MJ}^{-1}$ ve $0.19 \mathrm{~kg} \mathrm{MJ}^{-1}$; net enerji değerlerini ise sırasıyla $62584.37 \mathrm{MJ} \mathrm{ha}^{-1}, 69836.21$ MJ ha-1 ve $74405.43 \mathrm{MJ} \mathrm{ha}^{-1}$ olarak bulmuşlardır. Esengün ve ark (2007), Malatya ilinde kayısı üretiminde, enerji çıktı/girdi oranı ve enerji etkinliği değerlerinin 0.1-3 ha işletme büyüklüğü için sırasıyla 1.24 ve $0.24,>3$ ha işletme büyüklüğü için sirasıyla
1.31 ve 0.25 olduğunu belirtmișlerdir. Bu çalıșmada bulunan sonuçlarla, literatür sonuçları karşılaştırıldığında, işletme büyüklüğü artışına bağlı olarak enerji çıktı/girdi oranı ve net enerji değerlerinin artış gösterdiği ve dolayısıyla Esengün ve ark. (2007), Unakıtan ve ark. (2010), Şehri (2012) sonuçları ile benzerlik gösterdiği görülmektedir.

Askari ve ark. (2014) patates tarımında en yüksek enerji etkinliğinin 10 hektardan büyük işletmelerde, en düşük enerji etkinliğinin ise 1 hektardan düşük işletmelerde elde edildiğini ve bu sonuçların alan arttıkça enerji etkinliğinin arttığını gösterdiğini ifade etmişlerdir. Ayrıca, arazi mülkiyeti, deneyim, uygulanan tarım sistemi ve alan gibi faktörlerin enerji verimliliği üzerine etkilerini değerlendirmişler ve alan dışındaki tüm faktörlerin anlamlı bir etkisinin olduğunu belirtmişlerdir. Houshyar ve ark. (2014) daha az gübre, su ve kimyasal ilaç kullanılmasının özellikle tarımsal alanlardaki sürdürülebilirliği önemli bir şekilde artırdığını ve sürdürülebilirliğin azaltılmış toprak işleme sistemlerini uygulayan büyük çiftliklerde daha iyi olduğunu ifade etmişlerdir. $\mathrm{Bu}$ açıklamalar çalışma alanında toprak ve su kaynaklarını koruyan toprak işleme sistemleri ve girdi kullanımın azaltıldığı ve etkinleştirildiği tarımsal uygulamaların kullanılmasının enerji etkinliği dolayısıyla sürdürülebilirlik açısından ne kadar önemli olduğunu göstermektedir.

\section{Sonuç}

İşletme alanı büyüklüğü arttıkça kârlılık ve enerji üretkenliği artmaktadır. Çalışmada elde edilen sonuçlar, aspir üretimde enerji girdisini azaltmak 
için kimyasal gübre enerjisi ve yakıt enerjisi girdisine dikkat edilmesi gerektiğini göstermektedir. Şüphesiz daha yüksek verim elde edebilmek için kimyasal gübreleme yapılmaktadır. Ancak gübrelemenin doğru zamanda, doğru tekniklerle ve gerekli olan miktarda yapılması gerekir. Bunun yanında kimyasal gübre enerji tüketimini azaltmak için yeşil gübreleme ve hayvan gübresi kullanımı olmak üzere iki alternatif vardır. Çalıșmanın yapıldığı İç Anadolu Bölgesi Sivas İlinde hayvancılık potansiyeli dikkate alındığında hayvan gübresi kullanımının artırılmasının mümkün olduğu görülmektedir.

Yakıtın (dizel yakıtı) tarımsal sistemlerdeki enerji dengesindeki oranı belirli ürünlerin üretimi için gerekli olan mekanizasyon uygulamalarına bağlı olarak \%10-70 aralı̆̆ında değişmektedir. Tüketilen yakıt miktarını etkileyen en önemli etmenlerin başında üretim alanının büyüklüğü gelmektedir. Çalışma derinliği, toprak tipi, gübreleme uygulamaları, mekanizasyon düzeyi, taşıma mesafesi ve yöntemi dikkate alınarak uygun makine seçiminin yapılması ile daha yüksek enerji kullanım etkinliği sağlanacaktır. $\mathrm{Bu}$ durum, alet ve makinaların daha efektif kullanımı ve tarla kapasitelerinin yükselmesi ile birlikte yakıt tüketiminin azalması ve üretim sistemlerinin daha verimli kullanılması anlamına da gelmektedir.

\section{Kaynaklar}

Acaroğlu, M., 2006. Katı ve Sıvı Biyokütle (Biyodizel) Üretiminde Enerji Bilançolarının Karşılaştırılması. Tarımsal Mekanizasyon 23. Ulusal Kongresi, 6-8 Eylül 2006, s: 103-108, Çanakkale.

Allali, K., Dhehibi, B., Kassam, S.N., Aw-Hassan, A., 2017. Energy Consumption in Onion and Potato Production within the Province of El Hajeb (Morocco): Towards Energy Use Efficiency in Commercialized Vegetable Production. Journal of Agricultural Science, 9(1): 118-127.

Alpkent, N., 1984. Tarımda enerji kullanımı ve enerji tasarrufu. Milli Prodüktivite Merkezi Yayınları No: 296, Ankara.

Altuntaş, E., E, Özgöz, S. Dede, 2018. Orta Karadeniz Geçit İklim Kuşağında Silaj Mısır Üretiminde Toprak İșlemenin Enerji Kullanım Etkinliğine Etkisi. Selçuk Tarım ve Gıda Bilimleri Dergisi, 32 (3): 238-248.

Altuntaş, E., O.N. Bulut, E, Özgöz, 2019. Kuru tarımda farklı toprak işleme sistemleri ile buğday üretiminin enerji kullanım etkinliği analizi. Anadolu Tarım Bilimleri, 34 (1): 57-64.
Anonim, 2014. Sivas İl Gelişme Planı, Sivas.

Anonim, 2016. Gıda, Tarım ve Hayancılık Bakanlığı, İstatistik Veri Ağı, Sivas Gürün.

http://iva.tarim.gov.tr/Raporlar, (10.01.2017).

Arıkan, M., 2011. Adana ilinde kolza üretiminde enerji kullanımı. Cukurova Üniversitesi Fen Bilimleri Enstitüsü Tarım Makinaları Anabilim Dalı, Yüksek Lisans Tezi, Adana.

Askari, U., Sheikh Davoudi, M.J., Mansourifar, M., 2014. Economic and Energy Analysis for Potato Production in North of Khuzestan Province (Case Study: Gotvand City). Bulletin of Environment, Pharmacology and Life Sciences, 3(5): 72-78.

Babaoğlu, M. 2007. Aspir ve tarımı. Trakya Tarımsal Araştırmalar Enstitüsü, Edirne.

Baran, M.F., Gökdoğan, O., 2016. Determination of energy balance of sugar beet production in Turkey: A Case Study of Kırklareli Province. Energy Efficiency, 9: 487-494.

Baran, M.F., Karaağaç, H.A., 2014. Kırklareli Koşullarında İkinci Ürün Ayçiçeği Üretiminde Enerji Kullanım Etkinliğinin Belirlenmesi, Türk Tarım ve Doğa Bilimleri Dergisi, 1 (2): 117-123.

Berkman, A., 1996. Sürdürülebilir tarımsal kalkınmada araștırma ve geliștirme faaliyetlerinin yeri ve Güneydoğu Anadolu Projesi. Tarım ve çevre ilişkileri sempozyumu Bildiri Kitabı, Mersin.

Bojaca CR, Schrevens E., 2010. Energy assessment of periurban horticulture and its uncertainty: case study for bogota, Colombia. Energy, 35: 2109-2018.

Cross, T., 1998. Machinery cost calculation methods. Agr. Extension Service, The University of Tennessee, Inst. of Agriculture. AE\&RD No.13, 8 pages.

Doering, O.C., 1980. Accounting for energy in farm machinery and buildings. In: David Pimentel, editor. Handbook of energy utilization in agriculture. FL, USA: CRC Press, Inc; p. 9-14.

Esengun, K., Erdal, G., Gündüz, O. ve Erdal, H., 2007. An economic analysis and energy use in stake-tomato production in Tokat province of Turkey. Elsevier, Renewable Energy, 32: 1873-1881.

Gifford, R.C., 1986. Agricultural Mechanisation in Development: Guidelines forStrategy Formulation. FAO Agricultural Services Bulletin, No:45, FAO, Rome, 77s

Golaszewski, J., van der Voort, M., Meyer-Aurich, A., Baptista, F., Balafoutis, A., Mikkola, H.J., 2014. 
Comparative Analysis of Energy Efficiency in Wheat Production in Different Climate Conditions of Europe. Journal of Agricultural Science and Technology B, 4: 632-640.

Gözübüyük, Z., Çelik, A., Öztürk, İ., Demir, O. M., Adıgüzel, C., 2012. Buğday üretiminde farklı toprak işlemeekim sistemlerinin enerji kullanım etkinliği yönünden karşılaştırılması. 27. Tarımsal Mekanizasyon Ulusal Kongresi, Samsun.

Hetz, E.J., 1992. Energy utilization in Chilean agriculture. Agric Mech. In Asia Afr. and Lat. America, 23: 52-56.

Houshyar, E., Davoodi, M.J.S., Almassi, M., Bahrami, H., Azadi, H., Omidi, M., Sayyad, G., Witlox, F., 2014. Silage corn production in conventional and conservation tillagesystems. Part I: Sustainability analysis using combination of GIS/AHPand multifuzzy modeling. Ecological Indicators, 39: 102-114.

Ișıklı E., Ișın, S., 1991. Son on yılda türkiye'de tarım sektörünün verimlilik açısından değerlendirilmesi, I. Verimlilik Kongresi, Bildiriler, Milli Prodüktivite Merkezi Yayınları, No:5454, 345 s, Ankara.

Kardoni, F., Jami-Al Ahmadi, M., Bakhshi, M.R., 2015. Energy Efficiency Analysis and Modeling the Relationship between Energy Inputs and Wheat Yield in Iran. International Journal of Agricultural Management and Development, 5(4): 321-330.

Karaağaç, H. A., Aykanat, S., Gültekin, R. ve Baran, M.F., 2014. Adana'da ana ürün mısır üretiminde enerji kullanım etkinliğinin belirlenmesi, Doğu Akdeniz Tarım Araștırma Enstitüsü, Adana.

Kizılaslan, H., 2009. Input-output energy analysis of cherries production in Tokat province of Turkey. Applied Energy, 86: 1354-1358.

Kurt, O., Uysal, H., Demir, A., Özgür, U., Kılınç, R., 2011. Samsun Ekolojik Koşullarına Adapte Olabilecek Kıslı Aspir (Carthamus tinctorius L.) Genotiplerinin Belirlenmesi Üzerinde bir Araștırma. Anadolu Tarım Bilimleri Dergisi, 26 (3): 212-216

Öğüt, H., Oğuz, H., 2006. Biyodizel (Üçüncü Milenyum Yakıtı). Nobel Yayınları. 13-24, 169-176.

Özcan, M.T., 1985. Mercimek hasat ve harman yöntemlerinin iş verimi kalitesi, enerji tüketimi ve maliyet yönünden karşılaştırılması ve uygun bir hasat makinası geliştirilmesi üzerine araştırmalar. C..Ü. Ziraat Fakültesi Tarımsal Mekanizasyon Bölümü, Adana.
Özgöz, E., Altuntaş, E., Asiltürk, M., 2017. Effects of soil tillage on energy use in potato farming in Central Anatolia of Turkey. Energy, 141: 1517-1523.

Öztürk, H.H., Barut, Z.B. 2005. Türkiye Tarımında Enerji Kullanımı. Türkiye Ziraat Mühendisliği, Teknik Kongresi, Ankara. Sayfa 1253-1264.

Pishgar Komleh, S.H., Keyhani, A., Rafiee, Sh., Sefeedpary, P., 2011. Energy use and economic analysis of corn silage production under three cultivated area levels in Tehran province of Iran. Energy 36: 3335-3341.

Rahamatalla, A.B., Babiker, E.E., Krishna, A.G., El Tinay, A.H., 1998. Changes in chemical composition, minerals and amino acids during seed growth and development of four safflower cultivars. Plant Foods for Human Nutrition, 52(2): 161-170.

Sefeedpari, P., Rafiee, S., Pishgar Komleh, S.H., Ghahderijani, M., 2012. Source-wise and operationwise energy use analysis for corn silage production, a case study of Tehran province, Iran. International Journal of Sustainable Built Environment, 1: 158166.

Shahin, S., Jafari, A., Mobli, H., Rafiee, S., Karimi, M., 2008. Effect of Farm Size on Energy Ratio for Wheat Production: A Case Study from Ardabil Province of Iran. American-Eurasian J. Agric. \& Environ. Sci., 3(4): 604-608.

Singh, S., Pannu, C.J.S. ve Singh, J., 2000. Optimization of energy input for raising cotton crop in Punjab. Energy Conversion and Management, 41(17): 1851-1861.

Șehri, M. 2012. Adana yöresi pamuk üretiminde enerji kullanım etkinliği ve maliyet analizi. Yüksek Lisans Tezi, Çukurova Üniversitesi Fen Bilimler Enstitüsü. 74 s., Adana.

Unakitan, G., Hurma, H. ve Yılmaz, F., 2010. An analysis of energy use efficiency of canola production in Turkey. Energy (2010): 1-5.

Wang, P., Ou, S., Peilin, C., 1999. Optimization of condition for safflower cell culture and accumulation of cellicolous product tocopherols. China Journal of Biotechnology, 15(4): 231-237.

Weiss, E.A., 2000. Safflower. In: Oilseed Crops, Blackwell Sci. Ltd., Victoria, Australia.

Zangeneh, M., Omid, M., Akram, A.A., 2010. comparative study on energy use and cost analysis of potato production under different farming technologies in Hamadan province of Iran. Energy, 35: 2927-2933. 